\title{
Una etnografía triste en el sur de Chile. Tancredo Pinochet Le Brun en el fundo de su excelencia*
}

\author{
A sad ethnography in the south of chile. Tancredo Pinoche Le \\ Brun in the hacienda of his excellence
}

Miguel Alvarado Borgoño*

\section{RESUMEN}

En este artículo nos centramos en una lectura de corte antropo-

Palabras clave:

lógico del texto Inquilinos en la hacienda de Su Excelencia, del Tancredo escritor chileno Tancredo Pinochet Le Brun. Vemos aquí una antropología y específicamente una etnografía intuitiva, pero que apela a los principios contemporáneos de la antropología poético literaria y a los orígenes del discurso antropológico naPinochet Le Brun, antropología intuitiva, etnografía. cional definidos prototípicamente por la obra de Rodolfo Lenz y Nicolás Palacios.

\section{SUMMARY}

In this article, we focus on an anthropological reading of the text Keywords: Tancred "Tenants in the hacienda of His Excellency", by the Chilean writer Pinochet Le Tancredo Pinochet Le Brun. We see here an anthropology and specifically an intuitive ethnography, but one that appeals to the contemporary principles of literary anthropology and to the oriBrun, intuitive anthropology, gins of national anthropological discourse prototypically defined ethnography. by the work of Rodolfo Lenz and Nicolás Palacios.

Este artículo se inscribe en el proyecto de investigación de la Universidad del Bío Bío no 2050355, IF/R ejecutado en los años 2020-2021.

** Chileno. Doctor en Ciencias Humanas, mención Literatura y Lingüística (UACH), antropólogo (Universidad de Chile) y sociólogo (Universidad Gregoriana). Postdoctorado (Universidad de Frankfurt y de Göttingen en Alemania). Profesor jornada completa en el Departamento de Ciencias Sociales, Universidad del Bío-Bío, sede Chillán. Ciudad de Chillan, Chile, e-mail: malvarado@ubiobio.cl 
En el fondo, no se trataba tanto de descubrir lo verdadero y lo falso como de comprender de qué modo los hombres habian ido superando contradicciones.

(LÉVI-STrauss 56)

\section{El acaecimiento de la denuncia}

En la segunda década del siglo pasado un periodista, escritor y pedagogo chileno, don Tancredo Pinochet Le Brun, dio una suerte de "salto al vacío" en tanto disfrazado de inquilino y sin autorización alguna, acudió a visitar - en pleno dominio de la oligarquía terrateniente chilena-, una de las haciendas del presidente de la República de entonces Juan Luis Sanfuentes, generando un texto que lo interpelaba directamente respecto de la deplorable situación de sus inquilinos. Se trata de un salto al vacío no solo como expresión de periodismo de investigación (tipo textual, que en esa época no estaba conformado y que no se inicia para Chile aquí), sino de una narración generada desde un "yo rotundo", que es así mismo un "yo con otros", y esos otros eran los más desprotegidos de la sociedad chilena de entonces, como los inmigrantes haitianos o de otra nacionalidad que hoy se encuentran en una situación de desprotección invisibilizada. Tras su narración hay una tremenda tristeza, la tristeza de alguien que no puede entender cómo ocurren los hechos narrados, donde la injusticia es tan radical, y respecto de lo cual la clase política no hace nada frente a la miseria de medio millón de inquilinos chilenos que demuestra Tancredo Pinochet Le Brun.

Hay algo coincidente, un aire de familia, entre esta situación y toda la historia de Chile. Existe en Tancredo Pinochet Le Brun algo inusual para la época: su espíritu de tratamiento de la información a la manera de la generación de lo que hoy llamaríamos tipos ideales (en la perspectiva webereana) para generar teorías de alcance medio.

No creáis, Excelencia, que me imaginaba que vuestra hacienda fuera la mejor, ni la peor en el país. No, en otras partes el inquilino se da un poco menos "la bestia" pero era muy apropiada vuestra hacienda para tomarla como tipo y hacer un estudio sintético. (Pinochet Le Brun 85)

Sorprende pensar el valor y, sin duda, el indagador empeño, por la inicua situación de medio millón de chilenos a principios del siglo 
XX. ¿Cómo podía ser noticia algo que estaba a ojos vista? Más que una labor periodística, la de Tancredo Pinochet Le Brun disfrazado de inquilino en una hacienda del presidente de la República es un testimonio moral, y de lo cual surge la pregunta: ¿qué motivó a este hombre extraordinario - del mismo modo que movió a Gusinde a visitar a indígenas olvidados-, a buscar a los inquilinos a quienes clasifica como esclavos? En vida a ninguno de los dos, Gusinde y Pinochet Le Brun, su trabajo de campo les trajo grandes beneficios, por lo que se trata de un curioso deseo por evidenciar lo sabido, pero encubierto. Pese a ello, sin duda significa un testimonio moral que representa lo mejor de nuestra cultura, eso que no es realizado por egolatría o por beneficio, sino por una obsesión por conocer algo que la mayoría pasaba intencionalmente por alto, como el costo natural para el equilibrio de la sociedad, en la lógica sacrificial del costo social de los valores. A este trabajo de campo intuitivo, le llamaremos etnografía, al menos hasta que los replanteamientos de las ciencias humanas latinoamericanas no le den otro nombre. Es una mirada acuciosa a cuerpos que en la perspectiva de Andrea Kottow (2017), en ese momento y contexto son "cuerpos inexistentes" obviados hasta lo invisible, nulos, falaces: cuerpos que no importan (Kottow 54). Sorprende la conciencia de un narrar lo invisible, y eso emparenta la antropología poético literaria (en adelante APL) chilena y la obra inicial de Tancredo Pinochet Le Brun, ya que ambas son formas de expresar lo que para la sociedad chilena de hace un siglo y de la actualidad también resulta invisible. En ese sentido, esta APL tiene en Tancredo Pinochet Le Brun un antecedente sólido, particularmente en su búsqueda de narrar lo oculto sin mayor preocupación por hacer o no ciencia normal. La especificidad de la APL se expresa en un conjunto de materiales textuales relacionados de manera sistémica con la historia reciente de Chile, aunque ello no sea siempre reconocido por los autores empíricos. La intertextualidad entre unos y otros da cuenta de los hitos históricos y de la existencia de lo que Marcel Proust pensó como el autor textual o literario distinto del autor biográfico (Zoberman 98).

Esta literatura poético antropológica es un producto original que surge a mediados del siglo XX en América Latina, y que tiene entre sus primeros impulsores a autores como el argentino Néstor García Canclini y el chileno Carlos Munizaga (Alvarado, "Una estética de borde..." 168). A su vez, guarda relación con los orígenes mismos de la ciencia 
antropológica y, por ello, comparte tanto sus virtudes como también sus limitaciones.

Asimismo, se emparenta con modas intelectuales y con formas de escritura difusas que, por el mismo carácter ambiguo que poseían, permitieron decir lo que no había sido dicho, o bien, no había sido enunciado de ese modo.

La etnografía es en sí un acto macilento de observar, especulando quien observa siempre respecto de un lector modelo y definido por los prejuicios de quien observa, observaciones que pueden modificarse en el momento mismo en que el etnógrafo realiza su tarea, como una síntesis entre la labor del hortelano y la del astrónomo, observando lo que en sí ya está delineado al interior del miramiento etnográfico, como apelación a un yo que ya está internalizado.

Es el caso de Bronisław Malinowky, iniciador de la etnografía científica, con su infinita paciencia y con su desparpajo para decir aquello en lo que no creía (así lo demostró su diario íntimo); porque siempre el etnógrafo está situado en un ojo saturado de sentido, y de un sentido cada vez más pulcro, mientras la etnografía cobra más valor social, por ello el encuentro entre etnografía y literatura ha sido un viaje costoso, que siempre se encuentra inconcluso. La etnografía no es algo que hagan solo quienes posean el título de antropólogo o etnólogo, es la observación que hacen quienes luchan entre sus prejuicios y el asombro frente a lo observado. Etnografía es realizar una narración de un escenario sociocultural desde una densidad que integra la búsqueda de lucidez (no necesariamente objetividad) y la visión del actor. Quizás la marca más sólida sea develar lo oculto, oculto por ser algo propio de otra cultura y que nos es desconocido, o algo que está en la cultura propia, pero vive la tragedia de ser invisible, tal como lo hace Pinochet le Brun, aunque no supiese que hacía una de las primeras etnografías sistemáticas de Chile narrando lo invisible.

\section{Una etnografía instintiva de los conmovidos en la generación de 1910}

Es interesante hablar aquí de Tancredo Pinochet Le Brun (paradojalmente tío abuelo del dictador chileno). En su obra Inquilinos en la hacienda de su Excelencia, publicada en 1916, hace una diatriba directa 
al presidente de la época, Juan Luis Sanfuentes, por la mala situación en la que vivían los inquilinos en la propia hacienda del primer mandatario:

Y bien me he dicho yo, Excelencia, ¿Por qué no ir a una de estas haciendas a vivir, aunque sea por poco tiempo, la propia vida del inquilino, codearme con ellos, vistiendo como ellos, comiendo como ellos, durmiendo como ellos? ¿Por qué no ser un inquilino? (Pinochet Le Brun 85)

Esta obra está teñida por la rabia y es lo que le da tanto un valor metodológico como literario. En primer término, metodológico, porque ensaya un método de campo intuitivo, en paralelo a los primeros trabajos de la etnografía científica europea. Desde esta perspectiva, se ha planteado que se trataría de una forma iniciática de periodismo de campo, pero este trabajo de Pinochet Le Brun no se desarrolla en el contexto pragmático comunicativo del periodismo como plantea Vicuña (10), sino de la crítica política inaudita, con un fundamento inusual para su época por el sustrato empírico que contiene, teniendo la forma más bien de una observación participante (etnografía) que de un trabajo de periodismo de denuncia, por su profundidad y sistematicidad, así como por su espectro de recepción como denuncia metódica sin la volatilidad de la mayoría de las denuncias periodísticas. De este modo, mientras los primeros sabios de la antropología realizada en Chile (Martín Gusinde, Ricardo Latcham y Tomás Guevara, entre otros) iniciaban también sus trabajos, en paralelo Pinochet Le Brun se internaba etnográficamente en lo invisible, sin preocuparse por el género del texto que producía, pero comprometido por el valor moral de aquello que denuncia, llevando a la luz lo que intencionadamente se ocultaba respecto de los inquilinos chilenos, realizando eso que en la ciencia moderna se denomina elicitación y que aquí es, por sobre todo, también un acto moral.

Por otra parte, esta crítica de Pinochet Le Brun tiene igualmente un marcado valor literario, porque hay algo de adictivo que embarga a sus lectores. Sin duda el autor embruja al lector con su escritura: como un pasaje de Truman Capote o del Apocalipsis, nos ocurre con este texto que a pesar de que su verdad nos es conocida y sabemos su conclusión, no podemos dejar de leerlo. A nivel poético construye metáforas como la del "inquilino esclavo" que no es producto de una histeria 
verbal, sino de una ira moralmente legítima, respecto de algo que para sus contemporáneos resulta lógico, en la lógica del mal naturalizado. Quizás como hoy, donde la concentración de la riqueza es algo típico y normalizado en nuestro medio, se requieren voces tan involucradas y sistemáticas para pensar diferente y, sobre todo, para decir que se piensa diferente, y ello nos fractura a nivel de identidad como nación, en la separación que genera la inequidad racionalizada. Coincidimos así con Cristian Gazmuri (2001) quien ve a Tancredo Pinochet Le Brun como un pensador de la crisis, crisis identitaria y crisis social, con contradicciones tremendas que se basan en una injusticia estructural en el primer centenario, inmerso en unas circunstancias con muchas semejanzas con nuestros actuales dilemas que se expresaron en la revuelta social de 2019 (Gazmuri 134).

El valor tan necesario de denunciar está muy presente en nuestro país a principios del siglo XX, particularmente en el impulso entregado a la generación de 1910, la llamada "generación del centenario", que contó con autores de los cuales el más destacado es Francisco Antonio Encina, cuya línea de pensamiento fue continuada por Tancredo Pinochet Le Brun, Guillermo Subercaseaux, Alberto Edwards, Luis Galdames y Alejandro Venegas Arrollo, entre otros. Teniendo su antecedente en el siglo XIX con la obra de autores como José Victorino Lastarria, Vicente Pérez Rosales, Diego Barros Arana, Luis Orrego Luco y Moisés Poblete; y, a su vez, proyectándose esta generación en las décadas posteriores en autores como Joaquín Edwards Bello, Darío Salas, Tomás Guevara, Alberto Cabero, Ricardo Latcham, Fausto Valdés Vergara, Luis Thayer Ojeda, Carlos Keller, Jorge González Von Mareés y Ricardo Donoso.

Hay pues una reacción, no solo respecto de la situación del "Chile de a pie", sino también de la soledad que involucra no contar con categorías analíticas que permitan la interpretación:

El mundo europeo ha puesto más interés en estudiar nuestros volcanes que nuestras sociedades, conoce mejor nuestros insectos que nuestra literatura, más los caimanes de nuestros ríos que los actos de nuestros hombres de Estado; i tiene mucha mayor erudición respecto del corte de las quinas i el modo de salar los cueros de Buenos Aires, que respecto de la vitalidad de nuestra democracia infantil. (Lastarria 11) 


\section{Gérmenes de una etnografía de agitación}

Desde la poética de esta etnografía de agitación, narración de lo inaceptable (entendida esta escritura de agitación como una narración que intenta ser límpida y sistemática, aunque el autor o autores tendrán conciencia de narrar un escándalo), Tancredo Pinochet Le Brun debió luchar contra el gesto nervioso, como también del mismo modo deberá batallar con los temores al ridículo y al castigo legal: debió ser algo que no es solo enunciación, debe ser algo profético, a la manera de Exequiel, Matatías o de nuestro Pablo de Rokha (manteniendo las diferencias, lo que no niega las similitudes). Así, coincidimos con Soledad Reyes en el carácter de agitación de un segmento de la escritura del Chile del bicentenario, ello en un tono de denuncia, que da cuenta de una crisis interna de la sociedad chilena del bicentenario por comprenderse a sí misma y para soñar un orden diferente que sea coherente (Reyes 9).

En su crítica abierta y valiente a la oligarquía de su época, nos dice Tancredo Pinochet Le Brun:

el hacendado, ha llenado a Santiago de palacios y automóviles, no como fruto del talento con que ha trabajado sus haciendas, sino de la forma en que ha explotado a los esclavos de la gleba. Más afín, Excelencia, no solo hay degeneración económica entre vuestros inquilinos. Hay también degeneración física. (Pinochet Le Brun 94)

El gesto interpretativo, que era una verdad para Lastarria, implicará contemporáneamente sin duda reconocer algo innegable y que hace urgente continuar el esfuerzo de interpretación de las grandes masas de nuestro país: la mayoría de los chilenos es descendiente de esos seres tiranizados, y la obra de Tancredo Pinochet Le Brun no es la etnografía de la mirada de la alteridad radical, sino un recuerdo remoto de la memoria ancestral que nos aplasta, porque no deseamos reconocer que somos los sucesores de ese sufrimiento. Lamentablemente nuestros abuelos ya no están para recordárnoslo.

El pensamiento de Pinochet Le Brun es ante todo una sensación de desarraigo, en el contexto del mismo centenario donde la denuncia de la situación del trabajador de la "hacienda de su excelencia" es también la extrañeza en su propio suelo, como señala Javier Pinedo: 
Un intenso sentimiento de vivir como extranjero en un país (el propio) no preparado para el combate de la modernidad. En el contexto global del centenario, Tancredo Pinochet coincide en que el tema de la decadencia nacional podía una vez más corresponder a una visión en ocasiones, exagerada, pues el país terminaba de salir triunfador de una guerra en la que había ganado enormes territorios a los países vecinos (...) no obstante, los réditos de ese triunfo militar no beneficiaban a los oprimidos del campo que él describe. (Pinedo Castro, "Apuntes para un mapa..." 34).

El efecto más concreto del texto de Pinochet Le Brun es reafirmar o al menos afirmar una sensación muy profunda en los inquilinos de su Excelencia, de un país extraño donde las guerras ni las demandas hacen eco en una elite que está tan sorda como lo están hoy en el siglo XXI; en ese entonces tampoco se invertía en paz social, tal como en la actualidad.

Si asumimos la etnografía como grafos, como escritura, como texto que habla desde el yo para traducir una cultura, y la antropología como ejercicio racional (en la acepción eurocentrada de este concepto) y expresión de un pensamiento reflexivo, que intenta generar verdad, aunque no acumularla, ni esclerotizarla, entonces nos parece un dato de realidad y un hecho propio de nuestra historia de la ciencia (a menos que hablemos de una etnografía del texto mismo), cosa que en sí no es despreciable: el paso desde la experiencia etnográfica hacia la reflexión antropológica es el camino casi obvio para generar una reflexión sustantiva. No obstante, el inconveniente está en la exigencia nomológica de crear leyes universales de la sociedad y la cultura, lo que aparentemente indicaría que nuestra ciencia ha fallado, quizás justamente por autoimponerse metas inadecuadas que ya eran absurdas para europeos como Dilthey o Schleiermacher, y para toda la tradición hermenéutica desde principios del siglo XIX en Europa, y también para el pensamiento latinoamericano en Bello, Rodó o Lastarria.

Lo adecuado es más bien una postura en algún sentido conservadora respecto de la historia de las ciencias: no se trata de progresar en una antropología hermenéutica, sino de realizar el esfuerzo ideográfico de la antropología desde la tradición antiilustrada generada, entre otros por Rousseau (1982), y que continúa en Latinoamérica con nuestros románticos: el esfuerzo por comprender ya fue realizado, no 
obstante, los megaproyectos desarrollistas lo anularon. Es que la ciencia positiva nubló algo que venía desplegándose desde los esfuerzos incluso de los cronistas de Indias, por ello el camino es volver a narrar y a reflexionar desde el fracaso de la ciencia positiva asociada al impulso moderno, pero sin duda nunca al estilo de la antropología posmoderna de la segunda mitad del siglo XX en Norteamérica, sino por el esfuerzo de autores como Claude Lévi-Strauss que en Tristes trópicos nos señaló un camino que ha sido seguido con altura por la APL en Chile hoy.

Es una suerte de hipnosis operada sobre el lector modelo del 1916, pues se asume que la realidad del inquilinaje es conocida, pero se trata de una anécdota en el devenir existencial. La irrupción de un texto que crudamente habla de higiene, relaciones asimétricas, humillación, mala alimentación, robo, etc., sorprende y provoca otro estado de conciencia, por ello su objetivo puede ser caracterizado como el de escandalizar:

Excelencia, Vos jamás habéis vestido andrajos (...) y no os podéis dar cuenta del sentimiento que experimenté. Para explicaros os diré que el señor Rodríguez me presentó a una dama y a causa de mi traje tal es el de mi transformación- me la presentó cuando yo ya estaba disfrazado de inquilino de vuestra hacienda y no fui capaz de darle la mano. ¿Creeréis, Excelentísimo Señor, que mi alma se había transformado de tal manera en esclavo de la gleba? (Pinochet Le Brun 90)

\section{El recurso a la metáfora}

El goce que produce la simbolización es sin duda el goce de la certidumbre, aunque es un goce estético que la metáfora contiene. Hay certeza e incertidumbre en narrar, y Tancredo Pinochet Le Brun, tal como los antropólogos experimentales de todo el mundo hoy, debió sufrir ese deseo de hablar cuando todos callaban respecto del inquilino, calificándolo valerosamente de ser un ser humano que vive en situación de esclavo, y gozando la actitud de hacer justicia en el texto, en el placer del sentido. Ello es lo que hace de la antropología en diálogo con la literatura un artefacto no peligroso aún, pero al menos incómodo para la antropología tradicional, no porque no pueda cooperar de manera plena en la superación de las carencias que vive nuestra sociedad, sino porque hay muy pocos dispuestos a cambiar su forma de escritura antropológica. 
Ya sabemos que un programa de investigación es ante todo escritural, es el esfuerzo contemporáneo del traductor cultural, y el programa de investigación de Tancredo Pinochet Le Brun fue su programa escritural, el cual desarrolló incluso con su cuerpo trasvertiéndose en inquilino, viviéndolo sin duda poéticamente:

Será porque estoy habituado a poner sinceridad en cada acto mío, yo no sé por qué será, Excelencia; pero os declaro que el acto de esa transformación, dentro de mi alma, era un acto fúnebre. Yo me posesionaba de mi papel, Excelencia. Es bello y alegre que muera una crisálida y nazca una mariposa; pero es triste y hace llorar, Excelencia, que muera un hombre y nazca una bestia (.. .) (Pinochet Le Brun 88)

El aporte de Paul Ricoeur (23) es epicentro teórico de este artículo y encarna un puente entre el plano pragmático y el hermenéutico para lograr una etnografía local y el poema en prosa. Su reunión se cumple bajo una influencia extraña, la de la música escuchada en el concierto; se encuentran en ella varios procedimientos que se hallan en las letras: sin saberlo, Pinochet Le Brun los recuperó.

El género, que por ello se convierte poco a poco en algo como la sinfonía, en comparación con el canto personal, deja intacto el antiguo verso, al que consagró un culto y atribuimos el imperio de la pasión y de los ensueños; en tanto este sería el caso de tratar, con preferencia (tal como sigue) ciertos temas de imaginación pura y compleja o intelecto: ya que no existe ninguna razón para excluirlos de la poesía, única fuente de un fundamento teórico consistente, esto como lazo definido desde la aceptación que Ricoeur (44) hace en su pensamiento del aporte pragmático lingüístico y el posterior desarrollo de una propuesta desde el concepto de "metáfora viva" que, aunque es heredera de la fenomenología existencial, se abre al aporte de algunas de las filosofías del lenguaje contemporáneas (pragmática, y hermenéutica particularmente), reconciliando el pensamiento británico empirista y norteamericano pragmático con el aporte del mentalismo continental.

Solo desde el recurso de la impresión íntima expresada en la metáfora es posible una etnografía, y así es viable la etnografía de Pinochet Le Brun. Quizás el punto más neurálgico de la poética de nuestro autor es la interpelación directa al presidente de la República: hace 
falta valor para ello, pero también talento para que lo dicho no parezca solo una diatriba vacía de belleza y especialmente de contenido. El académico Javier Pinedo Castro caracteriza la ensayística de esta generación como una de "metodología impresionista, pues definen al chileno en base a intuiciones (sin recurrir a las ciencias sociales) y con rasgos positivos o negativos en comparación con otras realidades culturales" (Pinedo Castro, "La ensayística y el problema..." 282). La necesidad expresiva no lo llevó a hacer ciencia, sino una etnografía intuitiva, que sin tampoco ser un periodismo espontáneo es una triste etnografía de la opacidad de las circunstancias que son difíciles de describir,

Pero principié a sentir algo raro, Excelencia, muy raro. Yo no os puedo explicar claramente esto, porque en mi mismo espíritu lo siento confusamente, principié a sentir la hostilidad de la atmósfera. ¿Cómo?, me preguntaréis. En la mirada de cada cual, en el gesto de asco que cada uno hace, sin sentirlo, sin imaginarlo, sin darse la más mísera cuenta, cuando miraba un andrajoso. No sacan un pañuelo para cubrirse las narices; no hablan estos espíritus hostiles; pero es un movimiento instintivo; es un gesto imperceptible casi, un algo que insulta, que oprime, que ofusca, Excelencia. (Pinochet Le Brun 91)

Si la antropología surge desde un empirismo fuertemente positivista en la traza que Bronisław Malinowky le imprime, es en el diálogo a nivel filosófico entre la escuela analítica de origen británico y el idealismo europeo desde donde es posible definir una hermenéutica antropológica, asumida no como epistemología, sino como ontología, donde la autorreferencia tenga un espacio, una cabida, en un entramado capcioso pero consistente. Tancredo Pinochet Le Brun hace antropología sin ser un antropólogo, en tanto realiza una operación racional desde la enunciación metafórica:

Mi voz era fuerte. Era un latigazo dado a un estafador. En mi lenguaje, en mi mirada, aquel boletero vio a algo más que a un inquilino. Y la prueba es que, en vez de tutearme, me dijo "señor", y me dio el diez, el que yo le tiro por la cara en medio del más severo reproche. (Pinochet Le Brun 93)

La propuesta de Ricoeur (87) es la búsqueda de un lenguaje hermenéutico para la descripción propia de las ciencias humanas, y par- 
ticularmente de la etnografía. Ello involucra asumir la invitación subyacente en Ricoeur, que busca generar un discurso centrado en un tipo de elaboración metafórica que sea, por una parte, consciente de la dimensión estética del enunciado, como también auténtica en su representación del mundo, con lo cual supere la mera intención moderna de generar taxonomías científicas, tan de moda en las antropologías de finales del siglo XX. Lo anterior, constituye un virtual aporte para la reflexión acerca de nuestra APL, lo cual conlleva un espacio no del todo seria y reflexivamente analizado en nuestro medio: el del discurso científico etnográfico como gestualidad retórica y simultáneamente poética. Ricoeur nos aclara que su obra:

(...) no pretende reemplazar la retórica por la semántica ni esta por la hermenéutica ni refutar una por otra; quiere legitimar cada punto de vista dentro de los límites de la disciplina que le corresponde y fundar la concatenación sistemática de los puntos de vista sobre la progresión de la palabra a la frase y de esta al discurso. (Ricoeur 6)

La APL como literatura de frontera (Carrasco y Alvarado 9), es un tipo de género discursivo, y quizás también una tendencia literaria, que aún no ha sido conocido, valorado, leído ni interpretado como tal, es decir, no ha sido canonizado por la institución literaria porque se ha desarrollado básicamente en publicaciones, congresos y diálogos propios de los espacios intelectuales de un sector determinado de las ciencias sociales contemporáneas.

Sus autores son antropólogos profesionales, es decir, personas con estudios universitarios de pre y posgrado, incorporados al campo laboral, académico e investigativo de las disciplinas antropológicas y arqueológicas y con participación en medios de comunicación característicos de los cientistas sociales. Han escrito tomando como modelos a escritores profesionales o antropólogos muy relevantes como Conrad, Teillier, Lévi-Strauss, Michel Leiris, etc. Y también en sus años estudiantiles dialogaron y compartieron con los grupos de poetas universitarios, asistieron a sus lecturas, discusiones, conocieron sus búsquedas, héroes, modelos y textos preferidos, sus entusiasmos, depresiones y soledades, incluso escribieron en ese ambiente sus primeros textos literarios y soñaron con la fama. 
Este espacio discursivo remite a dos órdenes principales de pensamiento, literario y antropológico, dado que estos constituyen una modalidad de la "mutación disciplinaria" en una de sus posibilidades. Como hemos escrito, la literatura en cuanto disciplina artística, gracias a su apertura permanente a la variedad, la experimentación y la transtextualidad, ha generado nuevas formas de discurso que han sido imitadas o han coincidido con desarrollos del conocimiento y disciplinas de distintas áreas que sobrepasan, debilitan, anulan y corroen sus límites. Esta estrategia consiste en la modificación de las reglas, modalidades, materias y procedimientos de conformación de textos de una disciplina artística, científica o filosófica, provocada por el traslado desde otra u otras disciplinas de esta o distinta condición. El resultado es la feliz confusión de ámbitos disciplinarios, géneros y tipos discursivos.

Sin embargo, detrás de este intento, que podría ser definido apresuradamente como metodológico, existe una intención más profunda de explicarlo que nos remonta al parentesco que Heidegger (1996) identifica entre pensamiento y poesía, nudo esencial a nivel teórico de este artículo. Este vínculo no se refiere a la identidad, sino que por el contrario, resulta de una relación tensional generada como resultado de la verdad identificada con la autenticidad, en el sentido heideggeriano, la cual solo puede ser conseguida desde el lenguaje poético en el que la metáfora representa un epicentro. Justamente en la palabra poética se da - según un concepto tomado de Jakobson- una referencia desdoblada: la metáfora como ámbito de la poética se refiere a la conexión entre mythos y mimesis (Ricoeur 56). Pinochet Le Brun no podría haber tenido el efecto social de interpelar pública y valientemente al presidente de la República, sin la necesaria combinación entre pensar y poetizar desde la interpelación valóricamente definida, que resulta sin duda un antecedente de la APL:

Tened paciencia; oíd todo lo que tengo que deciros, y serenamente meditad. Estáis en los comienzos de vuestro periodo presidencial; lo tenéis todo por hacer. Oíd. Os está hablando medio millón de inquilinos. Estos inquilinos han elegido como delegados para que os hablen a los propios sub-hombres de vuestra hacienda, y estos sub-hombres a su vez, me han nombrado su secretario. (Pinochet Le Brun 89) 
Es así como Ricoeur aporta básicamente un argumento respecto de la dicotomía entre la metáfora viva, la que surge de la comprensión hermenéutica del texto, y la metáfora muerta, la que emerge, por ejemplo, de los intentos de la ciencia tradicional positiva por generar taxonomías rigurosas, de manera tal que, como oposición a esta pretensión empirista moderna de vincular unidireccionalmente lenguaje, pensamiento y realidad, se puede generar un discurso enraizado en la autenticidad de la metáfora viva, que penetre nuestro lenguaje científico y lo refigure. Clifford Geertz (2001) habla justamente de la "refiguración" del pensamiento social como base de una propuesta interpretativa para la ciencia social contemporánea:

El análisis consiste pues en desentrañar las estructuras de significación (. . .) y en determinar su campo social y su alcance. Aquí, en nuestro texto, ese trabajo de discernir comenzaría distinguiendo las tres diferentes estructuras de interpretación que intervienen en la situación, los judíos, los bereberes y los franceses, y luego continuaría mostrando cómo (y por qué) en aquella época y en aquel lugar la copresencia de los tres elementos produjo una situación en la cual el sistemático malentendido redujo la forma tradicional a una farsa social. (Geertz 24)

\section{Lenz, antecedente de Tancredo Pinochet Le Brun}

No existiría la osadía de Tancredo Pinochet Le Brun, sin la etnografía de salvataje de Rodolfo Lenz. Todo el camino nos lleva a la etnografía de Tancredo Pinochet, nos arrastra a la aceptación de que la cultura vive en la palabra y solo de allí se hace vida. En el profético pensamiento de Rodolfo Lenz, ni la homogeneización cultural moderna, ni el actual cuestionamiento del empirismo etnográfico tenían una cabida por razones históricas. Ello se relaciona con su formación dentro del contexto de la tradición historicista alemana; esta imagen de padre tutelar nos sitúa frente a Lenz para asumirlo como un "sabio" producto prototípico de la tradición idealista e historicista alemana, que desde un antipositivismo, en una rigurosidad extraída de la veta filológica más primordial, une el aporte de la sistematicidad de la tradición filológica:

Para todos estos trabajos no tenía yo más preparación que la que dan los estudios de la filología comparada de las lenguas indoeuropeas y especialmente de las lenguas neolatinas, que con razón 
se considera como la más instructiva con respecto a los métodos científicos. (Lenz 5).

Lenz es levemente previo a nivel cronológico respecto de Pinochet Le Brun y su esfuerzo es del mismo talante. Con este tipo de afirmaciones Lenz se autodefine como heredero de una tradición de pensamiento europeo continental, desde autores como Giambattista Vico (1668-1744), quien destaca el papel de la intuición vertida en la voluntad. Voluntad de conocer por parte del investigador y voluntad de crear significados culturales, por parte del "otro" investigado, con lo cual a la "ciencia nueva", crítica del cartesianismo, se une el intuicionismo de sello romántico enarbolado por autores como Schopenhauer y Nietzsche.

Lenz trae a Chile una forma de entender la investigación cultural, admirada por Palacios y que probablemente desesclerotizó al periodismo chileno de la ambición positivista de separar sujeto objeto, generando una sociología imposible. El periodismo tiene como género más libertad, pero es algo más que periodismo a nivel conceptual, empírico y ético lo que Pinochet Le Brun hizo.

El aporte de Pinochet Le Brun es el de una ciencia que no se entiende a sí misma como ciencia normal, sino que responde a una hermenéutica de la cual él no tuvo probablemente noticia, aunque algo puede haberlo impregnado en sus viajes por Europa directa o indirectamente. Esta tradición abre a Lenz a la posibilidad de la "comprensión", superando la interpretación racional de corte positivista. Recordémoslo: Lenz es heredero directo, en nuestro contexto, de esta tradición cuestionadora de la analogización organicista y que se nutre más bien del desarrollo de las humanidades, entendidas como expresión de lo que Dilthey llama "las ciencias del espíritu". Lo que Lenz no explicita, se expresa en su actitud etnográfica, se hace vida en el modo comprometido de asumir el encuentro, en el trabajo de campo intensivo, solitario y original.

Si no fuera así, su modo de acceso al otro cultural, desde una perspectiva humanista, definiendo así la escucha de las voces ajenas, no hubiera podido realizar el esfuerzo de sistematización ejecutado por Lenz. No se trata de una explicación teórica desde este andamiaje conceptual, sino de la prueba innegable del uso profundo de estas con- 
cepciones, manifestado en su actitud de investigador que supera a sus coetáneos.

Lejos está Lenz de autores como Barros Arana, quien en su Historia de Chile reconoce la diferencia cultural solo como un resabio de lo arcaico evitable, pero que gracias a la evolución de la historia está por extinguirse. Vale la pena recoger un trozo de esa retórica etnocéntrica, que tanto mal hizo a nuestro sentido común:

Los viajeros más recientes que han estudiado las costumbres de estos salvajes, y entre ellos dos grandes observadores, tan sagaces como prolijos, el capitán Fitz-Roy y el célebre naturalista Darwin, confirman plenamente estas apreciaciones. "Cuando vemos a estos hombres, apenas se puede creer que sean criaturas humanas, habitantes del mismo mundo que nosotros". Y más adelante agrega: "Yo creo que el hombre en esta parte extrema de América es más degradado que en cualquier otro lugar de la Tierra". (Barros Arana 93)

En el solo contraste con este tipo de pensamiento Lenz hace vida la tradición romántica alemana, no la teoriza, la hace vida en el encuentro etnográfico y en la dialogía en la interpretación.

En el mismo momento que está tomando fuerza el naturalismo literario, en el que Flaubert escribe Germinal y retrata la situación de la clase obrera en marcha, personajes como Rodolfo Lenz o Tancredo Pinochet Le Brun desarrollaban un esfuerzo por describir no lo exótico, sino lo conocido, pero no valorado. Más que enseñar a mirar, enseñaron a reparar un olvido absolutamente voluntario. Entonces, ¿qué tipo de mimesis actúa aquí? No es obviamente la imitación de la realidad, sino una cocreación creativa, donde el indígena y el inquilino son formas de tipos ideales que pueden ser narrados, básicamente por razones éticas.

Necesitaríamos reescribir las historias de la literatura o las de la política para comprender el lugar que ambos escritores, Lenz y Pinochet Le Brun, ocuparon. Fueron autores de urgente necesidad respecto de los mapuches y los inquilinos, narraron cuerpos en ese momento ocultados, interesada y onerosamente, sujetos que no eran encubiertos sin mala conciencia, pero el conformismo hace que, al igual que hoy en casos como los de la migración a Chile, se naturalice su presencia y particularmente su padecimiento. 
Sin duda aquí no opera siquiera el esoterismo ni el exotismo, se trata de lo que no puede ser retratado porque tomar conciencia de su verdad histórica involucraría cambiar sus circunstancias de vida, si los grupos dirigentes son coherentes con los valores que a principio de siglo dicen enarbolar.

Nada es tan único en la mirada de Pinochet Le Brun y Lenz; algunas estrategias, la del periodista experimentado quizás, la del lingüista altamente calificado, pero ninguna de estas dotes permitiría superar la ceguera autoinfringida. ¿Qué le da a Pinochet Le Brun su profundidad? Sostenemos que es el escándalo, él no admite lo que ve, no lo naturaliza, quiere narrar no para componer un texto más, sino para remover conciencias y en especial las de la clase política, encabezada por el presidente de la República. Se trata de una interpelación, que en términos teológicos tendría un carácter profético, ya que a la manera de los profetas bíblicos, describe una situación y deja que los hechos mismos generen en el "oyente-lector" una admiración condenatoria; quizás intenta generar también vergüenza.

Como hemos dicho Tancredo Pinochet Le Brun fue escritor, pedagogo (probablemente alumno de Rodolfo Lenz en el Instituto Pedagógico) y crítico social, de múltiples talentos y un inusual valor para enfrentar la vida profesional y personal. Su texto En la hacienda de su Excelencia, tuvo más bien un sentido axiológico: no lo benefició, no le fue fácil; más bien es la sorpresa de encontrarse rodeado de medio millón de extraños, es decir, medio millón de "ciervos de la gleba" viviendo en condiciones inhumanas.

Él creía que hacía difusión, cuando lo que hacía era una hermenéutica (aunque no usara el término) desde el testimonio que presentó hace un siglo: a eso certeramente llamaremos etnografía. Así relata su peregrinaje etnográfico.

Excelencia, por cerca de diez meses he estado recorriendo nuestro país desde Santiago a Punta Arenas, habiendo hecho hasta ahora la mitad de mi peregrinación de estudio para completar el examen de la vida nacional desde uno a otro confín de la República. Sin prejuicios sociales ni políticos, he llevado la mirada investigadora a todos los pliegos de la actividad nacional; no he rehusado el champagne de los opulentos, ni el mate de los humildes; he alojado en palacios y en conventillos. (Pinochet Le Brun 2) 


\section{Palacios, el iniciador}

La aventura narrada por Tancredo Pinochet Le Brun tiene la aleatoriedad del cuento $E l$ sur, de Jorge Luis Borges, en el sorprendente deseo de alteridad rural por parte del citadino, ese deseo de diferencia que lleva a terrenos peligrosos, pero que como un mandato obliga a mirar y a remirar aquello que no le era ni grato ni familiar.

Pero su inspiración deviene en gran medida de Nicolás Palacios (1904) y, por supuesto, del libro: Raza chilena y de las obras asociadas a este y sus vinculaciones tanto con nuestro pasado como nación, como con nuestro presente, explorando la estructura teórica e ideológica que subyace a conceptos en la época relevantes tales como novedad, racismo, identidad, etc. Así, es necesario en futuras investigaciones revisar aquellas formas de acceso a la modernidad presentes en el libro Raza chilena, como también los antecedentes de la obra de Palacios y sus alcances teóricos y disciplinares que incidieron en las distintas formas de acceso a la diversidad: periodismo, literatura, sociología, historia, antropología, etc.

A través de la historia se ha realizado una lectura ideologizada, parcial e intencionada de la obra de Palacios, lo que ha implicado que se ignore su obra como texto fundante de la disciplina antropológica sistemática y aplicada, dejando de lado esta producción teórica en la academia, mientras es rescatada por grupos políticos más conservadores que la han utilizado como estructura argumental en la elaboración de políticas públicas relativas a migración, género, etc. Por ello, es necesario destacar la diferencia que establecemos entre "profesión antropológica" y "visión antropológica”. Es en esta segunda instancia en donde la lectura de Raza chilena sí ha sido considerada, pero aún se mantiene al margen de la formación de antropólogos debido a una suerte de "enmalditamiento" (Alvarado, La antropología... 56) de Palacios, que es visto solo como un escritor racista y xenófobo, lo que ha impedido contemplar toda la complejidad y aristas que reviste su propuesta, que no solo contiene ribetes ideológicos, sino también científicos, adscribiéndose de forma fiel a su contexto histórico.

Los intentos de narrar la alteridad se convierten en una ficción, ficción que es el lugar en el que se encuentra lo imaginario y lo simbólico (Lacan 45); lo imaginario es la visión del narrador y lo simbólico opera 
como el lenguaje que se utiliza en la narración. Sin lenguaje no hay texto, y en este forzoso encuentro se genera una suerte de etnoficción (Auge 7) engendrada por el narrador, el autor. Utilizando la lógica de Fernando Pessoa (Alvarado, La antropología... 8) y sus heterónimos, en la APL surgen autores que toman formas diversas: el etnógrafo, el sujeto, el nativo, el científico, el autor textual, etc. Pensando la narración ya sea desde lo colectivo o desde un yo que es estrategia, expresión de la intertextualidad en el marco de un sistema de heteronimias, ello en una superposición hipertextual, la APL utiliza estos recursos para narrar, sin caer en un "surrealismo sin inconsciente" (Clifford y Marcus 17), transformándose y proyectándose más allá de la visión posmoderna, mientras es definido por el juego que articula el contexto y los procesos psíquicos. La poética de Palacios es un fundamento de cualquier APL, bástenos recoger la poética del siguiente texto escrito a principios del siglo XX:

El alma de esa creación es que revela al verdadero artista, poeta y pensador:

Esa mujer que avanza el busto, los ojos con manos inquietas, es el más hermoso símbolo que haya creado artista alguno de la fuerza irresistible y ciega de los instintos que perpetúan la especie, dominando como es claro sumiso el organismo entero de la mujer. El escorzo es el del ansia muda pero ardiente; del ansia femenina pero honesta, porque es la voz de la Naturaleza que manda. (Palacios 370)

El lenguaje del roto espera su hombre (.. .) se ha publicado en diarios de Santiago una poesía en chileno dedicada a Rodolfo Lenz, lo que me induce a creer que, por insinuaciones de ese estudioso e inteligente profesor del Instituto Pedagógico de Santiago, el poeta ha empleado nuestra lengua en versos. Gracias para el profesor y para el poeta. (Palacios 123).

\section{La antropología poético-literaria como continuidad del experimento de Tancredo Pinochet Le Brun}

La APL es literatura como discurso en un sentido pragmático textual, debido a: su contexto de recepción, la apelación a los usos retóricos de la literatura o "metáfora viva" (Ricoeur 16), la intertextualidad con 
fuentes literarias y a sus metalenguas (Mignolo 8) que develan una crisis interpretativa de las ciencias sociales. Se trata de aquello que José Joaquín Brunner (2004) llamó el "crepúsculo de las ciencias sociales", para luego apelar al comienzo de nuevas narrativas: la APL es representación primordial de esta crisis y de este nuevo comienzo de nuestras formas de autocomprensión; da cuenta de manera verosímil la realidad sociocultural chilena, reflexionando teóricamente acerca de la base de formas metalingüísticas desarraigadas de la ciencia.

La APL es literatura en definitiva, no solo por las estrategias textuales que utiliza o los modos de lectura que la reciben, sino por sobre todo porque su origen está en las búsquedas y también en las crisis de las ciencias sociales, especialmente la antropología sociocultural, pero es solo la literatura la que le concede a los textos de este subcanon verosimilitud y legitimidad social. El campo científico intenta emular colonialmente a las ciencias sociales eurocentradas, dando lugar a una forma de expresión literaria. Esta manifestación no se debe a un diletantismo intelectual, sino que obedece a los límites de la misma ciencia para narrar y comprender, pero en este camino la ciencia deja de hacer ciencia para hacer literatura, una literatura con rasgos aún no del todo identificados: es entonces que este es un estudio necesario, propio de la ciencia literaria y puntualmente abocado a la literatura chilena y los nuevos lugares en donde emerge. Hay un lazo de parentesco directo junto con un aire de familia, entre el esfuerzo actual de la APL y la obra de Tancredo Pinochet Le Brun que aquí analizamos.

Existe siempre el intento de conocer el origen, el punto de partida, el "grado cero" (Barthes 9), asumiendo una suerte de linealidad en los procesos históricos y una coherencia imposible entre lo que suponemos y lo que realmente aconteció, generando interpretaciones que enarbolamos como verdades. En cambio, estos textos emanan de la necesidad de narrar para interpretar, en un ejercicio transcultural en donde se fusiona ciencia y literatura, emergiendo más allá de la cultura misma, convirtiéndose en una manifestación que canaliza el "deseo colectivo", imbricado en el acontecer sociohistórico y su necesidad de comprender. Tancredo Pinochet Le Brun es un hito soslayado, ya que la injusticia que narra, ni fue discutible o exagerada en su narración, como tampoco del todo superada; así representa un grado cero, que retoma a Lenz y Palacios y expresa sin decirlo, que la APL tiene sentido 
y utilidad en una historicidad donde más que la autoría es la escritura misma la que se transforma y mantiene su identidad:

(...) llenar el cacharro y con paso lento, extenuado, como de aflicción. Se retiraba el sub-hombre bañado en un chorro de sol. Era el desfilar de la miseria (. . .) el batallón de la pobreza. (Pinochet Le Brun 99)

Una vez abandonado este intento de encontrar una definición categórica, podemos renunciar también a definir estas formas textuales, ya sea como ciencia o como literatura, comenzando a entender a este subgénero practicado por Pinochet Le Brun en el texto que analizamos como una escritura de frontera, en donde la interpretación, el ejercicio del lector es la manifestación fundante que recrea y cocrea el texto, desde dentro del mismo, sin asumir una postura separada frente a la obra, sino integrándola, componiéndola, configurándola, convirtiendo estos textos generados por antropólogos en creación cultural incesante que surge "en el bosque y no en el laboratorio" (Bachelard 76), es decir, provienen de las necesidades de la literatura, el arte y la ciencia, y de las interpretaciones de la cultura que las configuran. Estos espacios forjan discursos, preguntas autorreferidas, que articulan nuevas inquietudes, sin planificación previa ni método científico alguno. En este sentido, Pinochet Le Brun también es un precursor:

El inquilino, resignado, sumiso, ha soportado generaciones de esclavitud. Todas las medidas se han tomado para que no despierte la conciencia de esta bestia humana. Pero no hay arquitectos capaces, Excelencia, que construyan murallas para detener la expansión de las corrientes civilizadoras. (Pinochet Le Brun 110)

Hay un momento en donde es posible ubicar el origen de la narración de la alteridad latinoamericana, anclado en el surgimiento de las elites intelectuales del siglo XIX - cuyo influjo se mantiene hasta el siglo XX-, el examen de ese momento de la historia nos permite observar cómo el eje del análisis de la realidad está centrado en una búsqueda expresiva sincretizada y no se define desde el logos occidental.

No podemos olvidar que la sociología, la antropología y en general las ciencias sociales, surgen en el entorno europeo como formas de responder a sus interrogantes, ancladas en la modernidad y los procesos de industrialización. Este eurocentrismo produce en la realidad 
latinoamericana una suerte de ambigüedad conceptual: debido a la distancia que nos separa del origen de estas ciencias no es casualidad que se genere esta reconversión en donde emerge un canon experimental y, de cierta forma, impreciso pero necesario para narrar y generar conocimiento situado en América Latina. Podemos decir así, que el intento de Pinochet Le Brun es político, pero quizás sin quererlo estaba ensayando las convenciones de una nueva forma de narrar: antes que la APL, antes que la antropología posmoderna y aún antes que la antropología de la pobreza.

\section{Conclusiones}

La etnografía de Tancredo Pinochet Le Brun lleva el sello de la tristeza -muy a la manera de los Tristes trópicos de Claude Lévi-Strauss- y aunque no conoce el escenario que describirá luego de su experiencia de campo, sí sabe que está repleto de opacidad antes aún de visitarlo, de otra manera no hubiera tenido tantos trabajos preparatorios y el interés mismo para hacer audazmente lo que hizo; en su época adoptó ocasionalmente el rótulo de periodismo, no obstante, no existía en esos momentos un canon textual que permitiera afirmar la existencia de un periodismo como sistema textual.

La mimesis realizada supone un lector modelo no del todo creyente, y lo que intenta es sorprender con el propio desconcierto que el texto genera. Tancredo Pinochet Le Brun genera un sistema de tipos ideales donde la categoría de "esclavo" ocupa un lugar fundamental. Esta tipología que incluye al administrador, la preceptora, los inquilinos y a los personajes exteriores utiliza como estrategia textual fundamental al presidente Juan Luis Sanfuentes, quien es un personaje arquetípico, porque el autor textual le hace presente la situación de sus peones e inquilinos, pero no supone su inocencia, más bien el sorprendido es el autor textual, aún se sorprende de que una persona civilizada se beneficie conscientemente de tal barbarie e inequidad.

La simultaneidad entre la denuncia de Tancredo Pinochet Le Brun y la antropología de salvataje de Gusinde o del mismo Guevara, hace pensar que la situación de degradación en que vivían los inquilinos de su "Excelencia" era parte de una situación general, en la cual algunas familias eran dueñas de la mayor parte de la riqueza que, junto a la in- 
tervención del capital extranjero, generan una situación de inequidad donde son descritos dos sujetos sociales que aún no son actores sociales en términos de la sociedad moderna: indios e inquilinos; no son proletarios, tampoco clase media emergente, sino que son en palabras de Franz Fanón plenamente los condenados de la tierra.

Podemos decir, sin exagerar, que hay una genealogía entre los textos de Lenz, los de la APL y este escrito de Pinochet Le Brun, no porque respondan a un sistema textual o a un canon genérico similar, sino porque su interés es el mismo, esto es, la alteridad que no se quiere reconocer y porque son la metáfora, el medio por el cual un hecho social complejo es relatado, y podemos hablar de la etnografía para referirnos a Tancredo Pinochet Le Brun, porque hay un grafos, un intento de narrar que es ético como retórica del escándalo.

\section{Referencias bibliográficas}

Alvarado, Miguel. "Una estética de borde: literatura antropológica chilena". Aisthesis. Revista Chilena de Investigaciones Estéticas, no. 61, 2017, pp. 167-187. https://doi.org/10.7764/aisth.61.9

Alvarado, Miguel. La antropología literaria. Aportes para la generación de un lenguaje intercultural. Santiago, Cuarto Propio. 2011. Impreso.

Auge, Marc. La guerra de los sueños: ejercicios de etnoficción. Madrid, Gedisa. 1998. Impreso.

Bachelard, Gastón. La formación del espiritu científico. México, D. F., Siglo XXI, 1987. Impreso.

Barros Arana, Diego. Historia de Chile. Tomo I, Santiago, Editorial Universitaria, 1999. Impreso.

Barthes, Roland. El grado cero de la escritura. México, D. F., Siglo XXI, 1989. Impreso.

Brunner, José Joaquín. "Sobre el crepúsculo de la sociología y el comienzo de otras narrativas". Celebración de los 40 años de Flacso en América Latina. Informe de actividades. Recuperado de http://flacsochile.org/biblioteca/pub/publicos/1997/ revista/002336.pdf el 20 febrero de 2014.

Carrasco, Iván y Alvarado Miguel. "Literatura antropológica chilena: fundamentos". Estudios filológicos, no. 46, 2010, pp. 9-23. 2010. http://revistas.uach.cl/pdf/efilolo/n46/art01.pdf 
Clifford, James y Marcus, George. Eds. Writing culture: The poetics and politics of ethnography. Berkeley, University of California Press, 1986. Impreso.

Gazmuri, Cristián. El Chile del centenario, los ensayistas de la crisis. Santiago, Instituto de Historia de la Pontificia Universidad Católica de Chile, 2001. Impreso.

Geertz, Clifford. El antropólogo como autor. Barcelona, Paidós, 2001. Impreso.

Heidegger, Martín. Caminos del bosque. Madrid, Editorial Alianza, 1996. Impreso.

Kottow, Andrea. "Cuerpos que (no) importan: Acerca de lo abyecto en la literatura chilena". Estudios filológicos, no. 60, 2017, pp. 151-168. http://revistas.uach.cl/index.php/efilolo/article/ view/1260/1281

Lacan, Jacques. Escritos I y II. México, D. F., Siglo XXI, 1984. Impreso.

Lastarria, José Victorino. La América. Santiago, Gante imprenta de Eugenia Vanderhaeghen, 1867. Impreso.

Lenz, Rodolfo. Estudios araucanos. Santiago, Imprenta Cervantes, 1895. Impreso.

Lévi- Strauss, Claude. Tristes trópicos. Barcelona, Paidós, 1984. Impreso.

Reyes, Soledad. El centenario de Chile (1910): relato de una fiesta, Santiago, Globo Editores, 2007. Impreso

Mignolo, Walter. Teoría del texto e interpretación de textos. México, D. F., Editorial de la Universidad Autónoma de México, UNAM, 1986. Impreso.

Palacios, Nicolás. Raza chilena Tomos I y II. Valparaíso, Imprenta y Litografía Alemana, 1904. Impreso.

Pinedo Castro, Javier. "La ensayística y el problema de la identidad, Chile 1960-1988". Los ensayistas. Chile: 1968-1988. Eds. José Gómez-Martínez y Francisco Javier Pinedo. Georgia, University of Georgia, Center for Latin American Studies, 1988. Impreso.

Pinedo Castro, Javier. "Apuntes para un mapa intelectual de Chile durante el Centenario:1900-1925". América sin Nombre, no. 16, 2011, pp. 29-40. Impreso.

Pinochet Le Brun, Tancredo. "Inquilinos en la hacienda de su Excelencia”. Memoria Chilena, 2018. Recuperado de http://www. memoriachilena.cl/archivos2/pdfs/MC0001497.pdf 
Ricoeur, Paul. La metáfora viva. Madrid, Trotta Editorial, 1991. Impreso.

Vicuña, Manuel. Fuera de campo: retratos de escritores chilenos. Santiago, Hueders, 2014. Impreso.

Zoberman, Pierre. "Et Proust créa le Juif, Le Discours et la Langue". Revue de Linguistique Française et d'Analyse du Discours, no. 1-2, 2009-2010, pp. 93-104. 